\title{
A Co-operative Numerical Analysis of Mycobacterium gastri, Mycobacterium kansasii and Mycobacterium marinum
}

\author{
By LAWRENCE G. WAYNE, ${ }^{1,2}$ L. ANDRADE, ${ }^{3}$ S. FROMAN, \\ W. KÄPPLER, ${ }^{5}$ E. KUBALA, ${ }^{6}$ GERTRUD MEISSNER ${ }^{7}$ AND \\ M. TSUKAMURA ${ }^{8}$
}

(Received 5 July 1978)

\begin{abstract}
A co-operative taxonomic study has been performed on slowly growing photochromogenic mycobacteria (Runyon Group I) and closely related organisms. Phenetic data on 54 strains, studied in seven laboratories, were collected and analysed by numerical taxonomic methods. Immunological properties and phage susceptibility patterns were analysed independently to establish correlation with numerical classification. Mycobacterium gastri, M. kansasii and $M$. marinum appeared as distinct well-defined clusters and the serological and phage data supported the resolution of these three species. A table of definitive properties is presented. Two strains each of $M$. simiae and $M$. asiaticum formed a loose cluster which was clearly separated from the previously mentioned three species; the small number of strains examined precluded the establishment of a list of definitive properties of these two species. It is concluded that the Runyon Groups, which provided a practical though arbitrary basis for establishment of a series of co-operative studies, have served their purpose and should now be supplanted by classification and nomenclature based on species.
\end{abstract}

\section{INTRODUCTION}

During the past 10 years the International Working Group on Mycobacterial Taxonomy (IWGMT) has undertaken a number of co-operative studies to clarify the systematics of the genus Mycobacterium. These studies have fallen into two categories. The first consisted of numerical taxonomic analyses of data derived from a large number of tests performed on selected sets of strains (Goodfellow et al., 1974; Kubica et al., 1972; Meissner et al., 1974; Saito et al., 1977; Wayne et al., 1971) and the second consisted of evaluation of the reproducibility of selected tests (Wayne et al., 1974; Wayne et al., 1976). The numerical analyses have provided baseline descriptions of a number of species and the IWGMT is continuing its activities in order to provide this information for all recognized species of cultivable mycobacteria. This is a report of the results of a co-operative study of an additional selected subset of slowly growing mycobacteria.

1 Veterans Administration Hospital, Long Beach, California 90822, U.S.A.

2 California College of Medicine, University of California, Irvine, California 92664, U.S.A.

3 Universidade Federal do Rio de Janeiro, Rio de Janeiro, Brazil.

* Olive View Medical Center, Sylmar, California 91342, U.S.A.

5 Tuberkulose Forschungsinstitut, Berlin-Buch, German Democratic Republic.

- Regional Administration of Public Health, Janov PO Mirosov, Czechoslovakia.

'Forschungsinstitut, Borstel über Bad Oldesloe, Federal Republic of Germany.

${ }^{8}$ Chubu Chest Hospital, Obu Chita-Gin, Aichi Ken, Japan. 


\section{METHODS}

The 54 cultures examined in this study were selected and assembled by A. Tacquet. The majority were photochromogenic slowly growing organisms (i.e. Runyon Group I). They were processed, coded and distributed by the American Type Culture Collection as described earlier (Wayne et al., 1971).

The investigation was carried out under the permissive philosophy and the other ground rules presented in the report of the first IWGMT study on scotochromogenic mycobacteria (Wayne et al., 1971).

Seven laboratories submitted a total of 189 characters per culture. Data from phage typing (12 features), immunodiflusion tests ( 3 features) and agglutinating serotype ( 3 features) were extracted from the main body of data for independent analysis. The remaining data were converted to binary form and coded according to the RKC system. Features that were not included in the original RKC code list (Rogosa et al., 1971) were assigned special numbers in the $\mathbf{9 8 0 0 0}$ series for this study. The data were submitted to $M$. I. Krichevsky for entry into the Micro-IS program at the Microbial Systematics Unit, National Institute of Dental Research. 'Irrelevant' and 'repetitious' data were deleted as in prior studies (Wayne et al., 1971). After deletions and consolidation of data, there remained 81 features upon which the numerical taxonomic analysis was based.

The analysis employed simple matching coefficients with sorting and sequencing according to unweighted average linkage. Cluster boundaries were defined after examination of $n \times n$ matrices and the mean internal matching score of each cluster and the mean matching scores between clusters were determined (Meissner et al., 1974). Feature frequency lists were also generated for each cluster.

\section{RESULTS}

Numerical analysis based on 81 pooled features separated the 54 strains into five clusters (Fig. 1). The mean internal matching score (m.i.m.s.) of each cluster and mean matching scores (m.m.s.) between clusters are presented in Table 1.

The distribution of 18 features with the greatest resolving power among the three major clusters is presented in Table 2. The criterion for inclusion of a feature in this table was that at least $85 \%$ of the strains in at least one cluster had to be positive and at least $85 \%$ of the strains in another cluster had to be negative.

An independent numerical analysis was performed with the data derived from tests of susceptibility to the 12 phages that were excluded from the main phenetic analysis. The 52 strains examined in this manner separated into three major clusters, which could be subdivided into a total of 15 phage patterns (Fig. 2). The last two strains in Fig. 2 represent $M$. fortuitum and were not considered further in this study. The sequence of phage patterns was re-ordered to permit comparison of clustering behaviour of the three major clusters in the 81-feature phenetic analysis with that in the phage susceptibility study (Table 3 ).

Phenol extracts of 45 strains were tested against three reference systems $(\phi 1, \phi 2$ and $\phi 3)$ by immunodiffusion analysis as described by Wayne (1971) and the results were tabulated according to clustering behaviour in the 81-feature phenetic analysis (Table 4).

Cluster 1 consists of seven strains, with a m.i.m.s. of $94 \%$ and a m.m.s. of $72 \%$ or less to all other clusters. It includes ATCC 25027, which corresponds to ATCC 15754, the type culture of $M$. gastri Wayne 1966. All seven strains were isolated over a four-year period in the same hospital, but from seven different patients. None was considered clinically significant. They exhibit a heterogeneity of phage type, being distributed among four susceptibility patterns, three of which are not shown by strains from any other cluster (Table 3). Phenol extracts of all seven strains exhibited the unique $M$. gastri $\phi 2$ immunoprecipitation line and the bacilli agglutinated only in the 'gastri' reference antiserum (Table 4). Based on a difference of $85 \%$ or more between frequencies of positive features in the tests listed in Table 2, M. gastri can be distinguished from cluster $2(M$. kansasii) on the basis of five enzymic properties (nos 1 , $3,4,5,6$ ), two growth properties (nos 11,12 ) and responses to three inhibitors (nos 13,14, 15). Similarly, $M$. gastri can be distinguished from cluster $3(M$. marinum) on the basis of five enzymic properties (nos $1,2,6,7,8)$, three growth properties (nos 10,11,12) and responses to five inhibitors (nos 14, 15, 16, 17, 18).

Cluster 2 consists of 35 strains with a m.i.m.s. of $86 \%$ and a m.m.s. of $72 \%$ or less to all 


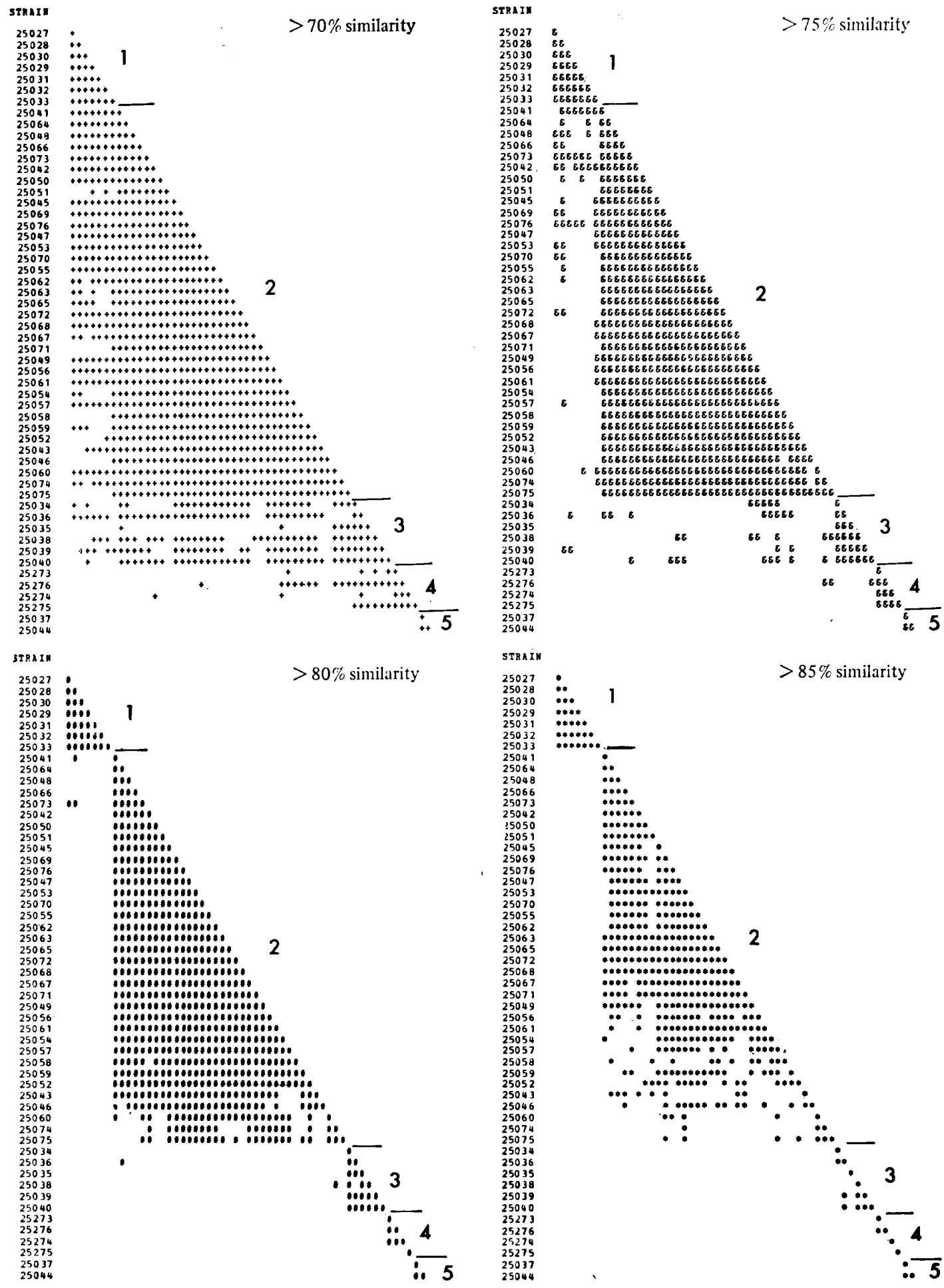

Fig. 1. Evolution of clusters at the 70, 75, 80 and $85 \%$ matching score levels, by unweighted average linkage, based on 81 features. 
Table 1. Matching scores $(\% \mathrm{~m}$.$) , expressed as mean intra- and intertaxon values \pm$ standard deviations for the five clusters as identified in the original analysis of pooled data, based on 81 features

\begin{tabular}{|c|c|c|c|c|c|c|c|}
\hline \multirow[b]{2}{*}{ Cluster name } & \multirow{2}{*}{$\begin{array}{c}\text { Cluster } \\
\text { no. }\end{array}$} & \multirow{2}{*}{$\begin{array}{l}\text { No. of } \\
\text { strains }\end{array}$} & \multicolumn{5}{|c|}{ Cluster no. } \\
\hline & & & 1 & 2 & 3 & 4 & 5 \\
\hline M. gastri & 1 & 7 & $\begin{array}{r}(94 \cdot 1) \\
( \pm 1.9)\end{array}$ & & & & \\
\hline M. kansasii & 2 & 35 & $\begin{array}{r}72.4 \\
\pm 3.3\end{array}$ & $\begin{array}{r}(86.2) \\
( \pm 4.8)\end{array}$ & & & \\
\hline M. marinum & 3 & 6 & $\begin{array}{r}68 \cdot 2 \\
\pm 4 \cdot 4\end{array}$ & $\begin{array}{r}70.9 \\
\pm 4.2\end{array}$ & $\begin{array}{r}(84.4) \\
( \pm 3.0)\end{array}$ & & \\
\hline M. simiae/asiaticum & 4 & 4 & $\begin{array}{r}61 \cdot 2 \\
\pm 3 \cdot 4\end{array}$ & $\begin{array}{r}64 \cdot 5 \\
\pm 4 \cdot 3\end{array}$ & $\begin{array}{r}69.8 \\
\pm 4.0\end{array}$ & $\begin{array}{r}(81 \cdot 8) \\
( \pm 3 \cdot 3)\end{array}$ & \\
\hline M. fortuitum & 5 & 2 & $\begin{array}{r}36.6 \\
\pm 3.3\end{array}$ & $\begin{array}{r}43 \cdot 0 \\
\pm 2 \cdot 8\end{array}$ & $\begin{array}{r}46.9 \\
\pm 3.2\end{array}$ & $\begin{array}{r}50 \cdot 8 \\
\pm 4.0\end{array}$ & $\begin{array}{c}(85 \cdot 2) \\
-\end{array}$ \\
\hline
\end{tabular}

Table 2. Distribution of 18 characters which show greatest resolving power among clusters 1,2 and 3

\begin{tabular}{|c|c|c|c|c|}
\hline \multirow[b]{2}{*}{ Character } & \multirow[b]{2}{*}{ No. } & \multicolumn{3}{|c|}{$\begin{array}{l}\text { Percentage frequency of positive } \\
\text { characters }\end{array}$} \\
\hline & & M. gastri & $\begin{array}{l}\text { M. kansasii } \\
2\end{array}$ & M. marinum \\
\hline $\begin{array}{l}\text { Enzymic activity } \\
\text { Propionamidase } \\
\text { Nitrate reduction, } 24 \mathrm{~h} \\
\text { Nitrate reduction, } 4 \mathrm{~h} \\
\text { Catalase, }>45 \mathrm{~mm} \text { foam } \\
\text { Catalase resists } 68^{\circ} \mathrm{C} \\
\text { Peroxidase } \\
\beta \text {-Esterase } \\
\text { Pyrazinamidase }\end{array}$ & $\begin{array}{l}1 \\
2 \\
3 \\
4 \\
5 \\
6 \\
7 \\
8\end{array}$ & $\begin{array}{r}100 \\
100 \\
0 \\
0 \\
0 \\
0 \\
0 \\
0\end{array}$ & $\begin{array}{r}0 \\
100 \\
96 \\
100 \\
100 \\
100 \\
46 \\
0\end{array}$ & $\begin{array}{r}0 \\
0 \\
0 \\
33 \\
83 \\
100 \\
100 \\
100\end{array}$ \\
\hline $\begin{array}{l}\text { Growth } \\
\text { At } 40{ }^{\circ} \mathrm{C} \\
\text { At } 25^{\circ} \mathrm{C} \\
\text { Pigmented } \\
\text { Photochromogenic }\end{array}$ & $\begin{array}{r}9 \\
10 \\
11 \\
12\end{array}$ & $\begin{array}{r}14 \\
14 \\
0 \\
0\end{array}$ & $\begin{array}{l}94 \\
83 \\
97 \\
94\end{array}$ & $\begin{array}{r}0 \\
100 \\
100 \\
100\end{array}$ \\
\hline $\begin{array}{l}\text { Resistant to } \\
\text { p-Nitrobenzoate, } 500 \mu \mathrm{g} \mathrm{ml}^{-1} \\
\text { Ethambutol, } 1 \mu \mathrm{g} \mathrm{ml}^{-1} \\
\text { Toluidine blue, } 300 \mu \mathrm{g} \mathrm{ml}^{-1} \\
\mathrm{NH}_{2} \mathrm{OH} . \mathrm{HCl}, 500 \mu \mathrm{g} \mathrm{ml}^{-1} \\
\text { Isoxyl, } 50 \mu \mathrm{g} \mathrm{ml}^{-1} \\
\text { p-Aminosalicylate, } 200 \mu \mathrm{g} \mathrm{ml}^{-1}\end{array}$ & $\begin{array}{l}13 \\
14 \\
15 \\
16 \\
17 \\
18\end{array}$ & $\begin{array}{l}0 \\
0 \\
0 \\
0 \\
0 \\
0\end{array}$ & $\begin{array}{r}89 \\
100 \\
100 \\
11 \\
0 \\
6\end{array}$ & $\begin{array}{r}67 \\
100 \\
100 \\
100 \\
100 \\
100\end{array}$ \\
\hline
\end{tabular}

Within each type of test character, the order has been arranged such that characters which achieve similar distinctions a ppear together.

other clusters. These strains exhibit the properties of $M$. kansasii Hauduroy 1955; phenol extracts of 26 of the 32 strains tested by immunodiffusion yielded the specific $\phi 1$ line characteristic of this species and cells of 28 of the 35 strains tested agglutinated in 'kansasii' reference serum (Table 4). Three strains exhibited very rough colonial morphology, and these agglutinated spontaneously and failed to yield the $\phi 1$ antigen; two of these exhibited the most common (2d) phage pattern. All but two of the strains were photochromogenic. Strain ATCC 25041 was scotochromogenic, agglutinated spontaneously, failed to exhibit the 
STRAIN

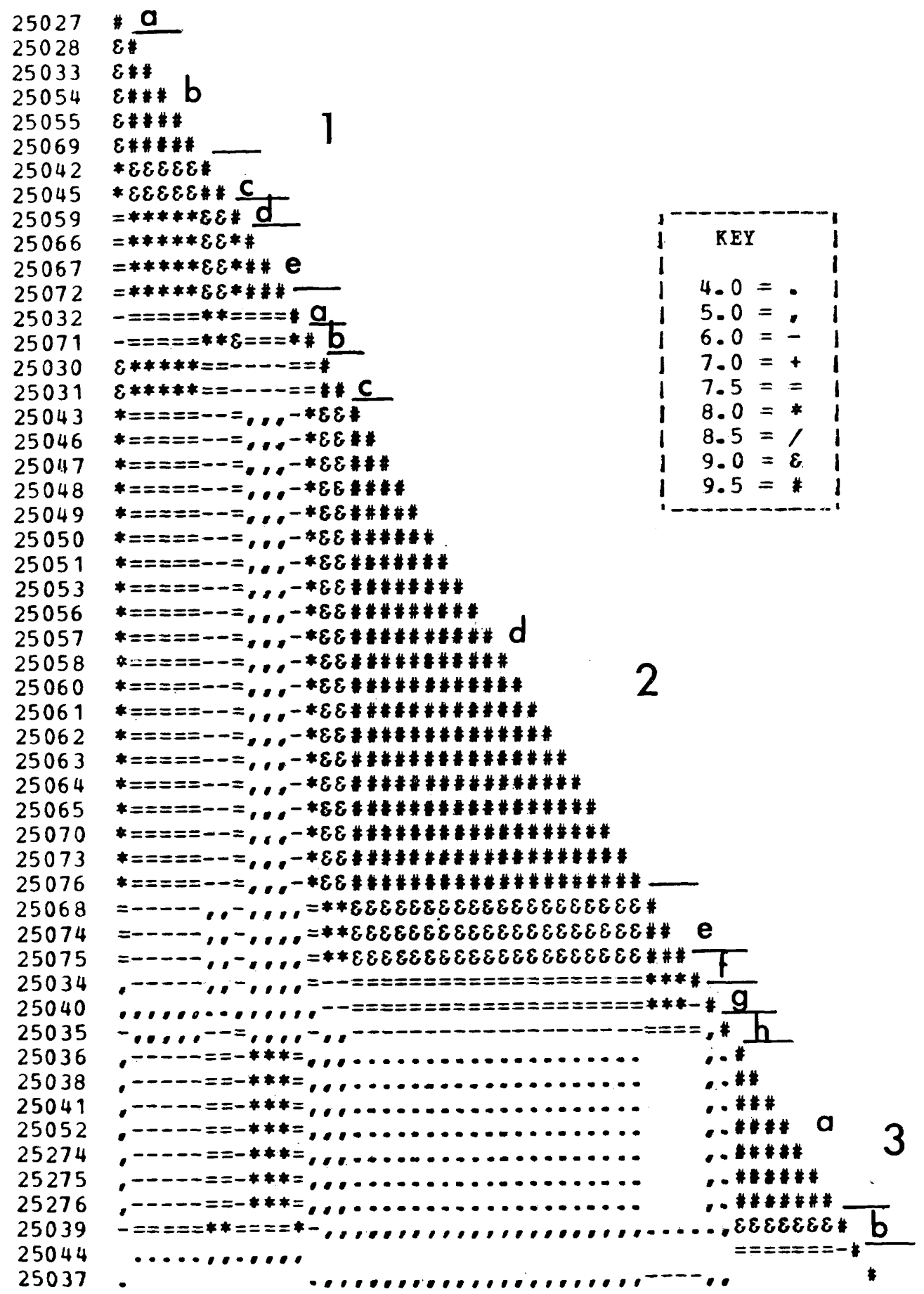

Fig. 2. Clustering of strains by unweighted average linkage according to susceptibilities to 12 phages. The numbers in the key represent $\% \mathrm{~m} / 10$. 
Table 3. Distribution of 47 strains according to phage susceptibility pattern and phenetic cluster

\begin{tabular}{|c|c|c|c|c|c|c|c|c|c|c|c|c|c|c|}
\hline \multirow{2}{*}{$\begin{array}{l}\text { Phage } \\
\text { pattern }\end{array}$} & \multicolumn{12}{|c|}{ Lysis by phage: } & \multicolumn{2}{|c|}{$\begin{array}{l}\text { No. of } \\
\text { strains } \\
\text { exhibiting } \\
\text { pattern } \\
\text { in cluster }\end{array}$} \\
\hline & $29 A$ & 310 & 340 & 29 & 338 & 337 & 352 & 345 & 32 & 12 & 28 & 56 & 1 & 2 \\
\hline $2 a$ & + & . & + & . & . & + & . & . & . & . & . & . & 1 & 0 \\
\hline $2 c$ & + & + & + & + & + & + & . & . & . & . & . & . & 2 & 0 \\
\hline 1a & + & + & + & + & + & . & . & . & . & . & . & . & 1 & 0 \\
\hline $1 b$ & + & + & + & + & . & . & . & . & . & . & . & . & 2 & 3 \\
\hline Ic & + & + & + & . & . & . & . & . & . & . & . & . & 0 & 2 \\
\hline le & + & + & . & . & . & . & . & . & . & . & . & . & 0 & 3 \\
\hline Id & + & + & + & . & . & . & + & . & . & . & . & . & 0 & 1 \\
\hline $2 b$ & + & + & + & . & . & + & + & . & . & . & . &. & 0 & 1 \\
\hline $2 d$ & + & + & + & + & + & + & + & . & . & . & . & . & 0 & 20 \\
\hline $2 \mathrm{e}$ & + & + & + & + & + & + & + & + & . & . & . & . & 0 & 3 \\
\hline $3 a$ & . & . & & . & . & . & . & . & . & . & . & . & 0 & 2 \\
\hline $3 b$ & . & . & + & . & . & . & . & . & . & . & . & . & 0 & 0 \\
\hline $2 \mathrm{f}$ & + & + & + & + & . & + & + & + & + & . & . & . & 0 & 0 \\
\hline $2 \mathrm{~g}$ & + & . & . & + & + & + & + & + & . & . & . & . & 0 & 0 \\
\hline $2 \mathrm{~h}$ & + & + & + & . & + & . & + & + & + & . & . & . & 0 & 0 \\
\hline
\end{tabular}

Table 4. Distribution of serotypes as determined by agglutination of whole cells and by immunodiffusion of phenol-soluble $(\phi)$ cell extracts

\begin{tabular}{|c|c|c|c|c|c|c|c|c|c|}
\hline \multirow[b]{3}{*}{ Species } & \multirow[b]{3}{*}{ Cluster } & \multicolumn{8}{|c|}{ No. of strains showing serotyping reaction specific for: } \\
\hline & & \multicolumn{2}{|c|}{ M. gastri } & \multicolumn{2}{|c|}{ M. kansasii } & \multicolumn{2}{|c|}{ M. marinum } & \multicolumn{2}{|c|}{ None } \\
\hline & & Agg.* & $\phi 2 \dagger$ & Agg. & $\phi 1$ & Agg. & $\phi 3$ & Agg. & $\phi$ \\
\hline M. gastri & 1 & 7 & 7 & 0 & 0 & 0 & 0 & 0 & 0 \\
\hline M. kansasii & 2 & 0 & 0 & 28 & 26 & 0 & 0 & 7 & $6 \%$ \\
\hline M. marinum & 3 & 0 & $\mathbf{0}$ & 0 & $\mathbf{0}$ & 6 & 4 & 0 & 2 \\
\hline
\end{tabular}

* Agglutination of ceils, as performed in laboratory 4.

+ Specific line of identity with phenol extract of cell, as performed in laboratory 1 .

$\ddagger$ Three of these were very rough strains.

$\phi 1$ antigen, and resisted lysis by any of the phages tested. ATCC 25046 was non-pigmented, but was positive for the $\phi 1$ antigen, agglutinated in 'kansasii' reference antiserum, and exhibited the most common (2d) phage pattern. Only two of the strains in this cluster resisted lysis by all of the phages employed. The other 33 strains were distributed among seven lytic patterns; only three of these strains fell into a phage pattern that was shared with two $M$. gastri cultures. The features providing maximum resolution between $M$. gastri and $M$. kansasii were listed in the description of cluster 1 . Resolution between $M$. kansasii and cluster 3 (M. marinum) is based on three enzymic properties from Table 2 (nos 2, 3, 8), one growth property (no. 9) and responses to three inhibitors (nos 16, 17, 18).

Cluster 3 consists of six strains with a m.i.m.s. of $84 \%$ and a m.m.s.of $71 \%$ or less to all other clusters. It includes ATCC 25034, which corresponds to NCTC 2275, the type culture of M. marinum Aronson 1926; it also includes ATCC 25040, which corresponds to ATCC 11564 , which is listed in the 1976 ATCC catalogue as a Norden reference strain of ' $M$. balnei', a synonym of $M$. marinum. Two of the strains resisted lysis by all of the phages employed. Each of the other four strains exhibited a unique phage pattern not shared by any other culture in the study. Phenol extracts from only four of the strains exhibited the unique $M$. marinum $\phi 3$ immunoprecipitation line but cells of all six strains agglutinated with ' marinum' 
antiserum. The other properties providing greatest distinction between $M$. marinum and $M$. gastri and $M$. kansasii were listed above.

Cluster 4 is a more heterogeneous taxon (m.i.m.s. 82\%) which comprises four strains that are separated from all other clusters (m.m.s. $\leqslant 70 \%$ ). Included in this cluster is ATCC 25276, the type culture of $M$. asiaticum Weiszfeiler et al. 1971 . ATCC 25274 also bore the epithet $M$. asiaticum, but ATCC 25273 was received as $M$. simiae. The most peripheral strain in this cluster, ATCC 25275, is the type culture of $M$. simiae Weiszfeiler et al. 1965. Cultures ATCC 25274, 25275 and 25276 were resistant to all 12 phages employed; ATCC 25273 was not tested. It is noteworthy that only one of four laboratories that performed the niacin test obtained a positive result with ATCC 25275 , and none with ATCC 25273 . Although niacin accumulation is considered an important feature of $M$. simiae, it has been found to be only erratically demonstrable, even under highly standardized testing conditions (Wayne et al., 1976). Similarly, only two of four laboratories found both ATCC 25273 and 25275 to be photochromogenic, which is also in agreement with excessive variability noted in this property for this species under standardized conditions (Wayne et al., 1974). Strains ATCC 25274,25275 and 25276 were tested and failed to agglutinate with the three reference sera employed. Because of the small size and heterogeneity of cluster 4 , its features are not included in Table 2.

Cluster 5 consists of two strains of rapidly growing mycobacteria that resembled $M$. fortuitum. They were not considered further in this study.

\section{DISCUSSION}

A major spur to the intensive study of the taxonomy of mycobacteria in the past two decades was provided by the work of Timpe \& Runyon (1954), who demonstrated a correlation between colony texture and mode of pigmentation of slowly growing mycobacteria, and their association with human disease. They proposed a tentative classification into three groups, and applied the term 'atypical' to members of these groups, taking care to specify that this term was not meant to imply any special relationship to Mycobacterium tuberculosis. It is of some interest that the original groups designated I and III at that time both consisted of strains that 'develop pigment after standing at room temperature', but differ from one another in terms of roughness of the colony. In unsigned correspondence (Veterans Administration - National Tuberculosis Association Cooperative Study of Mycobacteria, 1955) published a year later, Runyon mentioned the role of light in the development of pigment of mycobacteria, and applied the term 'photochromogenic'. The Runyon Groups, as we know them today, appear to have been formally defined in 1958 (Runyon, 1958, 1959), and comprised four categories. Group I consisted of slowly growing photochromogens, Group II of slowly growing scotochromogens, Group III was changed to consist of slowly growing 'non-photochromogens' and Group IV was added to include an assortment of rapid growers. In retrospect, Group III as originally defined by Timpe \& Runyon (1954) could have included rough colony types of $M$. kansasii, which would fall into the later definition of Group I.

Throughout this early period, it was recognized that the Group designations were only a temporary device to be used until a more complete and systematic classification could be developed. Because of the convenience and usefulness of the Groups they were quickly and tenaciously adopted by clinicians and laboratory personnel and their use persists to this day.

When the IWGMT initiated co-operative studies on 'atypical' mycobacteria it was necessary to adopt some arbitrary limits on the range of sets of strains to be examined at any one time. The arbitrary boundaries selected were those of the Runyon Groups. Nevertheless, it was already recognized that these Group boundaries did not necessarily confine strains with a high taxonomic affinity to one another, and appropriate adjustments were made in the composition of the test sets. Thus, in recognition of similarities between 
$M$. intracellulare and $M$. scrofulaceum, a few strains of the former were included in the Group II study (Wayne et al., 1971) and a few of the latter in the Group III study (Meissner $e$ t al., (1974). Similarly, although $M$. gastri meets the criteria for Group III, it also has sufficient similarity to $M$. kansasii to warrant its inclusion in the present study as well as the prior one.

In the original description of $M$. gastri (Wayne, 1966) its similarity to $M$. kansasii was noted. Norlin et al. (1969) and Stanford \& Grange (1974) were subsequently unable to distinguish between these two species by immunodiffusion analysis of bacillary products. This is in contrast to the observations of Magnusson (1971) who measured specificity differences in skin test reactions of sensitized guinea-pigs and was able to distinguish $M$. gastri from $M$. kansasii on this basis. Both the immunodiffusion and the skin sensitivity techniques tend to provide resolution among mycobacteria at the species level.

The numerical taxonomic data from the present study are in good agreement with those from an earlier co-operative study (Meissner et al., 1974) in which strains of M. gastri were compared with a selected set of non-pigmented strains of $M$. kansasii, i.e. $M$. gastri forms a homogeneous cluster which is well differentiated from $M$. kansasii. Each of the three major clusters in the present study was homogeneous and distinct from the other two, in terms of agglutinating serotype, but this does not necessarily help resolve a question of species status since this property is known to provide only subspecific resolution, at least in the $M$. avium complex (Meissner et al., 1974). On the other hand, multiple agglutinating serotypes have not been observed within the species $M$. gastri, $M$. kansasii or $M$. marinum. It may be argued that the homogeneity of the $M$. gastri strains described in this study is a reflection of the fact that they were all obtained from a single laboratory; other strains were not available when this study was initiated. The variety of phage patterns obtained, and the four year period over which the strains were isolated, suggest that these do not simply represent reisolations of a single strain.

The phage data present limited evidence for the separation of $M$. gastri from $M$. kansasii since two $M$. gastri strains shared a pattern (1b) with three $M$. kansasii strains. The separation between $M$. kansasii and $M$. marinum on this basis is more complete, since the pattern shared (3a) is indeed no pattern, but a resistance to all of the phages tested. The resistance of two strains of $M$. kansasii to all of the phages employed may reflect some modification of the surface of the cells, since both were rough, exhibited spontaneous agglutination, and yielded no $\phi 1$ antigen on extraction of the cells with phenol. However, two other rough strains of $M$. kansasii that yielded no $\phi 1$ antigen exhibited the most common (2d) phage susceptibility pattern. The two phage-resistant $M$. marinum strains both exhibited specific agglutination in 'marinum' reference antiserum and yielded the specific $\phi 3$ surface antigen. A high correlation is seen between specific agglutinating type and presence of a specific line in immunodiffusion of phenol extracts. Since the phenol-soluble antigens have been shown to absorb the agglutinating antibody from specific antisera (Wayne, 1971), these products probably represent the surface antigen responsible for specific agglutination of mycobacteria.

The numerical taxonomic data presented here provide clear definition of three species, $M$. gastri, M. kansasii and $M$. marinum. The different immunologic studies cited above both support and conflict with the separate species status of $M$. gastri. In the absence of any clear and binding criteria for definition and circumscription of bacterial species (Wayne, 1978), the results of the present study do not warrant a proposal to change the status of any of the three species cited above.

The species $\boldsymbol{M}$. asiaticum and $\boldsymbol{M}$. simiae had only recently been described when this study was begun, and only a few strains were included; no conclusions can be reached about their status from these data.

This report completes a series of permissive co-operative studies designed by the IWGMT to delineate the most commonly recognized species within the Runyon Groups of 'atypical' mycobacteria. A similar study of the $M$. tuberculosis complex of organisms has recently 
been completed and is under analysis (H. H. Kleeberg, personal communication). The IWGMT has recently initiated an open-ended co-operative study in which strains of slowly growing mycobacteria which do not belong to any of the species that were described in this series of studies may be entered on a continuing basis. It is anticipated that this programme will provide baseline information about some of the less commonly encountered species (e.g. $M$. simiae, $M$. asiaticum, $M$. malmoense) and also permit recognition of new species. Although extremely useful as a first approximation upon which to base initial taxonomic studies, the Runyon Groups have served their purpose and should now be supplanted by current classifications and nomenclature.

Supported in part by the Medical Research Service of the Veterans Administration.

\section{REFERENCES}

Goodfellow, M., Lind, A., Mordarska, H., Pattyn, S. \& Tsukamura, M. (1974). A cooperative numerical analysis of cultures considered to belong to the 'rhodochrous' taxon. Journal of General Microbiology 85, 291-302.

Kubica, G. P., Baess, I., Gordon, R. E., Jenkins, P. A., Kwapinski, J. B. G., McDurmont, C., Pattyn, S. R., Saito, H., Silcox, V., Stanford, J. L., Takeya, K. \& Tsukamura, M. (1972). A co-operative numerical analysis of rapidly growing mycobacteria. Journal of General Microbiology 73, 55-70.

MAGNusson, M. (1971). A comparative study of Mycohacterium gastri and Mycobacterium kansasii by delayed type skin reactions in guinea pigs. American Review of Respiratory Disease 104, 377384.

Meissner, G., Schröder, K. H., Amadio, G. E., Anz, W., Chaparas, S., Engel, H. W. B., Jenkins, P. A., KäPPler, W., KLeEberG, H. H., Kubala, E., Kubin, M., Lauterbach, D., Lind, A., Magnusson, M., Mikova, Z., Pattyn, S. R., Schaefer, W. B., Stanford, J. L., Tsukamura, M., WAYNe, L. G., Willers, I. \& Wolinsky, E. (1974). A co-operative numerical analysis of nonscoto- and nonphoto-chromogenic slowly growing mycobacteria. Journal of General Microbiology 83, 207-235.

Norlin, M., Lind, A. \& OUChterlony, O. (1969). A serologically based taxonomic study of $\mathrm{Myco}-$ bacterium gastri. Zeitschrift für Immunitätsforschung, Allergie und klinische Immunologie 137, 241-248.

Rogosa, M., Krichevsky, M. I. \& Colwell, R. R. (1971). Method for coding data on microbial strains for computers (Edition AB). International Journal of Systematic Bacteriology 21, A1-174A.

RunYon, E. H. (1958). Mycobacteria encountered in clinical laboratories. Leprosy Briefs 9, 21.

Runyon, E. H. (1959). Anonymous mycobacteria in pulmonary disease. Medical Clinics of North America 43, 273-290.

SAITo, H., Gordon, R. E., Juhlin, I., KäPPleR, W., Kwapinski, J. B. G., McDurmont, C., Pattyn, S. R., Runyon, E. H., Stanford, J. L., TÁrnok, I., TAsaka, H., Tsukamura, M. \& Weiszfeiler, J. (1977). Cooperative numerical analysis of rapidly growing mycobacteria. International Jourral of Systematic Bacteriology 27, 75-85.

Stanford, J. L. \& Grange, J. M. (1974). The meaning and structure of species as applied to mycobacteria. Tubercle 55, 143-152.
TIMPE, A. \& RunYon, E. H. (1954). The relationship of 'atypical' acid-fast bacteria to human disease. Journal of Laboratory and Clinical Medicine 44, 202-209.

Veterans Administration - National Tuberculosis Association Cooperative Study of MycoBACTERIA (1955). American Review of Tuberculosis and Pulmonary Diseases 72, 866-868.

WAYNE, L. G. (1966). Classification and identification of mycobacteria. III. Species within Group III. American Review of Respiratory Disease 93, 919-928.

WAYNE, L. G. (1971). Phenol-soluble antigens from Mycobacterium kansasii, Mycobacterium gastri and Mycobacterium marinum. Infection and Immunity 3, 36-40.

WAYNE, L. G. (1978). Mycobacterial taxonomy: a search for discontinuities. Annales de Microbiologie (Institut Pasteur) 129A, 13-27.

Wayne, L. G., Dietz, T. M., Gernez-Rieux, C., Jenkins, P. A., KäPPler, W., Kubica, G. P., Kwapinski, J. B. G., Meissner, G., Pattyn, S. R., RunYon, E. H., Schröder, K. H., Silcox, V. A., TACQUeT, A., TSUKamura, M. \& Wolinsky, E. (1971). A co-operative numerical analysis of scotochromogenic slowly growing mycobacteria. Journal of General Microbiology 66, 255-271.

Wayne, L. G., ENGbaek, H. C., ENGel, H. W. B., Froman, S., Gross, W., HaWkins, J., KäpPler, W., Karlson, A. G., KleeberG, H. H., Krasnow, I., Kubica, G. P., McDurmont, C., Nel, E. E., Pattyn, S. R., Schröder, K. H., Showalter, S., TÁrnoK, I., Tsukamura, M., VergmanN, B. \& WoLINSKY, E. (1974). Highly reproducible techniques for use in systematic bacteriology in the genus Mycobacterium; tests for pigment, urease, resistance to sodium chloride, hydrolysis of Tween 80 and $\beta$-galactosidase. International Journal of Systematic Bacteriology 24, 412-419.

Wayne, L. G., Engel, H. W. B., Grassi, C., Gross, W., Hawkins, J., Jenkins, P. A., Käppler, W. KleeberG, H. H., Krasnow, I., Nel, E. E., Pattyn, S. R., Richards, P. A., Showalter, S., Slosarek, M., SZabo, I., TÁrnok, I., TSUKamura, M., VergmanN, B. \& Wolinsky, E. (1976). Highly reproducible techniques for use in systematic bacteriology in the genus Mycobacterium: tests for niacin and catalase and for resistance to isoniazid, thiophene 2-carboxylic acid hydrazide, hydroxylamine and $p$-nitrobenzoate. International Journal of Systematic Bacteriology 26, 311-318. 